Med Princ Pract 2007;16:467-468

DOI: 10.1159/000107755

\section{The Reform of Medical Education}

David L. Robinson

Department of Community Medicine \& Behavioural Sciences, Faculty of Medicine, Kuwait University, Kuwait

The accelerating growth of medically relevant knowledge and technology must be welcomed but it is also important to recognise that it has created very serious problems in the domain of medical education since prospective physicians are required to absorb an ever increasing amount of information. This is especially true when students study the basic medical sciences during the first half of their degree program.

Almost every science discipline has some application in medicine so that the medical curriculum requires students to have had a good grounding in subjects such as Physics, Chemistry and Biology so that they can cope with the teaching offered by Medical Faculty Departments such as Biochemistry, Microbiology, Physiology and Pharmacology as well as that offered by the long established Departments such as Anatomy and Surgery.

The requirement that medical students should keep up with the constant expansion of knowledge across a broad range of science disciplines is unrealistic and counterproductive. The most obvious consequence is that it is increasingly difficult for students to cope with the sheer volume of information that is presented to them. Less obviously, there is little time for students to understand and assimilate information as enduring personal knowledge and this increases the likelihood that much of it may only be retained in memory long enough to pass the next examination.

Another consequence of the growth of scientific knowledge is that medical curricula must minimise exposure to those subjects such as history and literature that could help to provide the human perspective that physicians must have in order to satisfy the health care needs of the community they serve. Equally problematic, the increasing emphasis on science subjects ensures the preferential selection of students with a prior educational bias towards science and minimal exposure to non-science subjects. There is also reason to believe that such students are less likely to have the kind of personality profile that would be optimal for social interaction and the practice of primary-care medicine $[1,2]$.

Turning now to the clinical years, there have also been secular changes that exacerbate long-standing problems. In an excellent article on medical education reform, Whitcomb [3] refers to the 1984 report of a panel of distinguished educators set up by the Association of American Medical Colleges to review the education of medical students and to make recommendations on any chang- es that might be needed. These educators concluded that the rotations through different 'clerkships' in the main clinical departments were often little more than unstructured apprentice experiences that lacked clear learning objectives and did not contribute in a coherent manner to the general professional education of medical students [3, p. 9].

The short duration of these clerkships also limits their educational value. This has been further eroded because patients now spend less time in hospital so that students may only have 'snapshot' exposures to specific cases, which do not allow them to develop their capacity to interact with patients or to observe all aspects of the diagnostic and therapeutic process. There is also the problem that increasing pressure on clinical faculty to see more patients, and generate more income, tends to prevent them from spending adequate time with students. As Whitcomb [3, p. 5] points out, 'there are published reports indicating that, at the time of graduation, medical students too often lack fundamental clinical skills that they should have acquired during their clinical education'.

A very useful and informative overview of the curriculum reform process undertaken in recent years by many medical colleges in the USA has been provided by the publication of a set of ten reports from these institutions. In a foreword, written by $\mathrm{Co}-$ hen and Fox [4], respective Presidents of the Association of American Medical Colleges and the Milbank Memorial Fund who commissioned the report, it is stated that 'the good news is that many medical educators are implementing curricular changes that are responsive to the latest advances in biomedical science, to the social and policy sciences relevant to medical practice, to the burden of disease, to the organisation and financing of health care, and to the changing demography of the American population'.

They go on to state the bad news which is 'that most contemporary curriculum reformers have not yet been able to make necessary changes in the second two years of medical education, when students receive their first intensive education in clinical practice.' It is suggested in some of these reports that necessary reforms have still not been undertaken because many members of the clinical faculty do not believe that changes are needed.

In a more detailed review of these reports, Ludmerer [5], a Professor of Internal Medicine and History at Washington University, worries that 'the approaches described in the [medical college] reports are insufficient to prepare the nation's medical students properly for the practice of medicine in the 21st century'. Thus, it is evident that medical colleges have only been able to implement reform of the first two 'basic science' years of the medical curriculum where they have most control.

A particularly useful innovation has been the general trend towards a 'systems based' structure that provides a more efficient, better integrated, and more coherent teaching and learning experience. Another innovation has in some cases been a very substan-

\section{KARGER}

Fax +41613061234 E-Mail karger@karger.ch www.karger.com (c) 2007 S. Karger AG, Basel

$1011-7571 / 07 / 0166-0467 \$ 23.50 / 0$

www.karger.com/mpp 
tial reduction in the number of basic medical science lectures through the introduction of 'self-learning'. However, since any reduction in teaching must be compensated by self-learning, this reform does not address the knowledge explosion problem. In fact, the difficulties of students are aggravated if they must acquire the same amount of knowledge, in the same duration of time, without the guidance and assistance provided by lectures. Another cause for concern is that new subjects have been added to the basic sciences part of the curriculum in order to address complaints that sometimes arise from the present inadequacy of clinical teaching.

If it is accepted that medical students are currently required to absorb too much information, and that the problem will become worse in the future, then one must contemplate 'root-and-branch' reforms that will reduce the information burden. In essence, there must be a greater 'division of labour' within the medical profession, with corresponding changes in medical education, so that students are only taught what they need to know in order to function as specialists in a particular area of medicine - and this will include 'specialisation' in general practice or primary care.

Thus, instead of learning 'everything about everything', those who enter medical school would only be provided with the knowledge and skills required to perform the functions needed in one specific area of medical practice. This would mean that there would be a number of different and more focused curricula during the basic science years with a marked reduction in the amount of knowledge that an individual student would have to acquire. Similarly, there would be a more narrowly focused and better structured clinical education with students spending extended periods in those clinical departments in which they will ultimately serve.

What one can envisage are generalists who 'specialise' in the diagnosis of a broad range of different disorders, and have the aptitude, knowledge and special training required for personal and therapeutic interaction with patients. These generalists will not have expert knowledge in any of the established specialist areas of medicine but they will be responsible for patient care and have the main responsibility for interaction with patients and for coordination of the services provided by specialists.

In conclusion, it is suggested that medical education should be provided on the basis of the knowledge and skills needed to perform the functions required in a specific domain of medical prac- tice. This will reduce the knowledge burden, improve studentteacher ratios, and allow more time for the acquisition of knowledge and skills required in different specialist areas. It should also be possible to reverse the wasteful trend towards admissions on the basis of MSc and PhD science degrees that effectively increases the cost of medical education as well as restricting the range of aptitudes, educational backgrounds, and personal qualities that can be brought to bear on the practice of medicine.

It is suggested that the reform of medical education should begin with a careful review of community needs and the needs of individual patients in order to identify a set of corresponding ' job descriptions'. A detailed analysis of these job descriptions should be used to determine the specific knowledge and skills that are required in each case. This information can then be used to determine the structure and content of a number of different courses that can be taught in parallel, to different sets of students, in the same way as different courses are taught in other university faculties.

\section{References}

1 Robinson DL: In pursuit of knowledge. Int J Psychophysiol 2006;62: 394-410.

2 Robinson DL, Mohammed NHJ, Hassan LSA, Hussain NHD: Confidence of medical students in the application of elementary medical emergency procedures. Med Princ Pract 1997;6:119-128.

3 Whitcomb ME: Responsive Curriculum Reform: Continuing Challenges; in The Education of Medical Students: Ten Stories of Curriculum Change 2000. http://www.milbank.org/reports/americanmedicalcolleges/0010medicalcolleges.html

4 Cohen JJ, Fox DM: Foreword; in The Education of Medical Students: Ten Stories of Curriculum Change 2000. http://www.milbank.org/ reports/americanmedicalcolleges/0010medicalcolleges.html

5 Ludmerer KM: Curriculum Reform 2000: an analysis; in The Education of Medical Students: Ten Stories of Curriculum Change 2000. http://www.milbank.org/reports/americanmedicalcolleges/ 0010medicalcolleges.html

Prof. David Robinson

Department of Community Medicine \& Behavioural Sciences

Faculty of Medicine, University of Kuwait

PO Box 24923, Safat 13110 (Kuwait)

Tel. +965 5319485, Fax +9655338948

E-Mail robinson@hsc.edu.kw 